\title{
Research on the Basic Problems of Prevention and Control of Corruption Crimes in China Based on Big Data
}

\author{
Yuehong Wu, Yaming Fang \\ The college of political and law, Guangdong University of Technology \\ Guangzhou, Yuexiu District, Dongfeng East Road 729, China
}

\begin{abstract}
Big Data contains the law of social development and criminal governance, and how to prevent and control corruption crimes to adapt to the tide of big data is the key to carry out the management of the number of times in crime prevention and control. In this regard, China should pay attention to the issue of "big data crimes" from the grasp of the concept and characteristics of big data and corruption prevention and control of corruption. This paper starts a big data interpretation of corruption through the investigation of corruption prevention and control of China under the threshold of data theory and practice, analyzes the challenge of big data against the existing corruption prevention and control system in China, and then studies the implementation of data-driven implementation of the fine prevention and control of corruption crimes. This paper puts forward the precise prevention and control category of crimes, and further opens up the road to evolution. As a tactical extension of the daily management strategy, corruption prevention and control is put forward to solve the "shortcomings" of corruption crime governance under the organic integration of "manpower + science and technology" and "traditional + modern" governance technology, crimes, corruption crimes, and prevention of corruption crime application performance.
\end{abstract}

Keywords-Big data of crimes; Corruption crimes; Prevention and control; Crime governance mode

\section{INTRODUCTION}

Chinese society is entering the "risk society" as described by German sociologist Professor Beck, with the characteristics of modernization, industrialization and opening up. The artificial logic of uncertainty and the split status of social relations have brought difficulties to crime prevention and control. Corruption crime has long been the focus of social governance and criminal crime research. Most governments in the world regard the prevention and control of corruption as a headache. The process of informatization makes the social development trend contain the characteristics of big data. The use of technologies such as mobile media, social networks and mobile payment and the explosion of data and information have brought society from the IT era to the Data Technology (DT) era [1]. Before the 18th National Congress of the Communist Party of China, the Chinese government adopted a formal policy of "attacking primarily and prevention as a supplement" in the administration of corruption crimes in our country. After the 18th CPC Congress found out that corruption crimes, punishing corruption crimes and preventing corruption crimes are related to "strike-based prevention Supplemented by "criminal policy is equally important, and then the academic research on prevention and control of corruption crimes is developing rapidly. Today's era is the era of big data such as Internet + , artificial intelligence and cloud computing. All countries in the world are actively integrating into the big data wave. China released the "Action Plan for Big Data Development" in 2015. At the "2017 World Telecommunication and Information Society Day" conference held on May 17, 2017, relevant officials from the State Ministry of Industry and Information Technology (MIIT) said that China will build a nationwide big data center [2]. It can be said that the full use of big data in all walks of life in various countries of the world has achieved initial success. Under the big data technologies and concepts, big data is used to solve the current problem of corruption prevention and control in our country and improve the economic and social benefits of prevention and control of corruption crimes in our country It is very important.

\section{EXPLAIN THE BASIC ISSUES OF BIG DATA}

The "13th Five-Year Plan" proposal adopted by the Fifth Plenary Session of the 18th CPC Central Committee put forward the proposal of "implementing the strategy of national big data and promoting open sharing of data resources" to elevate big data to unprecedented heights. In 2017, the National Attorney General's Conference proposed that in order to comply with the development trend in the information era, take the development of e-government as a starting point and take the application of big data as the guide, and gradually realize the exchange and sharing of information resources with other political and legal departments and relevant administrative departments, Pay close attention to upgrade and perfect the unified business application system, comprehensively promote the construction of national procuratorial big data center, and accelerate the construction of intelligent quarantine "; On May 17, 2017, the Supreme People's Procuratorate issued the" Guidelines for Large-scaly Proceedings (2017-2020)", Analyzed the background and current situation of procuratorial big data construction and formulated the list of key tasks, 
which laid a solid foundation for the dataization direction of procuratorial work in the future.

The definition of big data, the academic community divergent opinions. In the international community, Gartner, a world-renowned IT research and consultancy firm, said: "Big data is a diverse, massive and growth-oriented information asset that generates strong decision-making power based on new processing paradigms, Insight and process optimization capabilities."[3] Nomura Research Institute, a well-known think-tank in Japan, said: "Big data is a collection of large amounts of data and information resources that are difficult to manage using the existing general technologies." According to Forrester, a well-known consulting firm in the United States, "Big data is to fill There is a gulf between information and your capabilities, turning information into insight into your business."[4] isible, the international community of scholars on the definition of big data, though different, but all stressed the big data contains information resources, complex, can be mined and other factors. In China, some scholars think: "Big data refers to the data combination that can not be perceived,

TABLE I The corruption case of judgment documents situation

\begin{tabular}{|c|c|c|c|c|}
\hline Court & Basic Court & Intermediate Court & High Court & Total \\
\hline National Courts[5] & 3115 & 408 & 32 & 3556 \\
\hline $\begin{array}{c}\text { Sample case number } \\
\text { of courts }\end{array}$ & 1545 & 314 & 20 & 1879 \\
\hline Coverage ratio & $49.60 \%$ & $76.96 \%$ & $62.50 \%$ & $52.84 \%$ \\
\hline
\end{tabular}

Big data, as a new type of technology architecture, is a new trend in the development of modern information technology. This paper argues that big data refers to a diverse, massive and based on a new processing paradigm that is vast in scope and generates strong decision-making power, insight, and process optimization capabilities As well as tremendous value of pending information. Has the following characteristics: 1. Big data is a data set. Big data is a set of data with large data capacity, multiple data types, fast growth and low value density. Large data capacity, that is, the magnitude of data has risen from $\mathrm{GB}$ to $\mathrm{TB}, \mathrm{PB}$ and even $\mathrm{ZB}$, can be called massive, huge or even excessive, and is still continuing to explode [9]; The data category is more data information from the original simple numerical, character and text to web pages, pictures, video, image and location information, such as semi-structured and unstructured data types; rapid growth that the timeliness of big data requirements Data processing can be done in real-time and fast. To achieve this goal, the hardware platform required to be used can also be updated synchronously, and technologies such as distributed computing, parallel computing, software engineering and artificial intelligence are applied to it.[10]The low value density means that the Internet is full of repetitive and fake information, often valuable information is more scattered and less dense. 2. Big data is a new generation of information system architecture and technology. Big Data is a next-generation information system architecture and highly-growth information asset over a period of time that is acquired, managed, processed and served by traditional information technology and software and hardware tools within tolerable time."[6]"Big data, or huge amounts of data, refers to massive, high-growth, and diverse information assets that require new processing models for greater decision-making, insight, and process optimization."[7]The so-called big data, refers to the data explosion in the era of massive data mining, analysis, and for the use of technological innovation, which hosts the platform is mainly focused on the Internet platform [8]. Can be seen that although the definition of big data domestic scholars have different opinions, but also mentioned the large capacity, pending processing, information resources and other factors.

Through the empirical analysis of the corruption case judgment documents that account for more than half of China's national courts and cases (see table 1 for details), we can find out some outstanding problems in China's court corruption cases and further analyze the characteristics of big data. Help. technology that enables the collection, storage, and correlation analysis of large numbers, diverse sources and diverse formats of data. 3. Big data represents a new way of thinking. Big data represents a new way of thinking ----- Big data thinking is a powerful cognitive world that can help people discover new knowledge, create new value, improve new abilities and form new formats from vast amounts of data about world's ability [11]. The function of big data in prevention and control of corruption in China: 1. Enhance the prevention and control of corruption crime initiative and rigor; 2.Increase the accuracy and effectiveness of crime prevention and combating corruption; 3.To help punish corruption crimes, corruption prevention and control to enhance the effectiveness of corruption;4 Conducive to improving the decision-making authority of the scientific, guiding and the development of personal corruption prevention and control policies. 


\section{The Status Quo of Prevention AND CONTROL OF CORRUPTION IN CHINA FROM THE PERSPECTIVE OF BIG DATA}

Chinese society is entering into a "risk society" as described by German sociologist Professor Beck, with the characteristics of modernization, industrialization and opening up. The artificial logic of uncertainty and the split status of social relations have brought tremendous difficult. Against this background, intelligence analysis, risk warning and information analysis techniques in the era of big data may provide new ideas for the scientific implementation of China's prevention and control of corruption crimes. However, from both theoretical and practical perspectives, the theory and practice of China's prevention and control of corruption are not satisfactory under the perspective of big data.

\section{A. Theory of prevention and control of corruption crime in China from the perspective of big data}

1) Rights conflict theory and the lack of means to detect corruption

In the field of criminology, the theory of the right conflict is the basic theory, which is developed from the theory of conflict in the western criminology. It conflicts with the value conflict and the cultural conflict to form the contradiction in any society. The concrete manifestation of the conflict is that the ruling class's penal system is criminalized. The basic idea of rights conflict theory is that the formulation and implementation of criminal law are closely related to the power of individuals or groups. The supervision and control by the government on society per se generally exist in the criminal justice, criminal, environmental, ideological or political prejudices Conviction and punishment.[15]Conflict among people is the normal state of all countries, and the rulers in society achieve the goal of conquering the ruled by the lawmaking and control of the law. This is especially so in the criminal law, in conquering and punishing the criminals to conquer the weak help the conqueror for the price. The perspective of the theory of rights conflict tends to view society as a group of people who pursue their own interests. "The whole process of legislation, law-breaking and lawenforcement has become a direct and direct reflection of the interests among the interest groups."[16]The power conflicts between the interest groups of corruption crimes and the interest groups that integrate the interests of the people and the interests of the nation are manifested in the crackdown on whistleblowers and the evasion of legal sanctions. Based on this, there will be regional and organized corruption and clues of corruption in corrupt crimes, which can not be dealt with promptly due to the asylum of corrupt officials and interest communities associated with it, and even the phenomenon of retaliation against whistleblowers.

In China, the procuratorial organs and government supervision departments all over the country have their own reporting centers. Reporting as the most direct means and the most effective way to find the anti-corruption struggle in the theory of right conflicts as the interest of the people and the state is of great significance. When the national discipline inspection and prosecution authorities file a case investigation of the cases, an average of more than $80 \%$ of the cases came from the report [17]. However, due to the protection of regional and organized corrupt criminal interest groups, the reporting mechanism is not running smoothly, the disposal of whistleblowing information is not in place and the reporting cost is high, which makes the method of detecting corruption ineffective. The poor reporting mechanism is mainly manifested in poor reporting channels, ineffective reporting and acceptance mechanisms and human intervention and leakages. The inadequate handling of reported information is mainly reflected in the seriousness of the cases of handling cases and the inefficient investigation and punishment of corruption crimes, And penalties are not in place, thus making the corrupt elements more rampant; the high cost of reporting is mainly reflected in the tedious reporting process, increasing reporting costs, whistleblowers are faced with various dangers and lack of whistleblower protection of basic rights mechanisms.

\section{2) Differences in communication theory and corruption} prevention culture

Differential communication theory is the western theory of criminology, that criminals before the crime through the familiarity of the surrounding environment, life experience has long been the definition of crime, it is clear that the criminal act is still to go because the perpetrator because of social and psychological process makes There is a new change in the definition of crime itself, and the new definition (the emerging definition of wrongdoing) can easily surpass the correct perception of crime in terms of conceptual acceptance, psychology, and circumstances Produce a crime The core argument is that although the criminal activity is learned from society or from others, the theory of differential interaction focuses on the definition of crime committed by individuals. The understanding of this core point is of great benefit to the application of the theory of differential interaction in preventing and controlling corruption crimes and also a good explanation for why the national level has consistently failed to eliminate corrupt crimes through strict punishments and rectification campaigns. The corrupt process is based on the fact that the original understanding of the crime of corruption was obtained through social and psychological factors, namely the subconscious acceptance between corrupt criminal groups or corrupt officials and the personal interpretation of the legalization of the definition of the criminal act Selfidentification, the more the self-identity caused by this wrong understanding leads to the more possibility of corruption crime.

According to the theory of differential communication, the analysis of the root causes of corruption crimes can guide the work direction in the field of prevention and control of corruption crimes. At this stage, the prevention and control of corruption, the lack of cultural manifestations are: lack of awareness of the importance of building a clean government culture, corruption and improper propaganda propaganda, the integrity of cultural construction and other issues. The lack of awareness of building an honest and clean culture is mainly due to the fact that some units and leaders understand the construction of an honest and clean government at the surface. Vigorous advocacy and support at the national level has become a slogan for localities and departments. Since leaders 
of different departments in different places pay more attention in varying degrees, the development of a culture of honest and clean administration in society has been extremely unbalanced. At the meeting, it was emphasized that it was hard to implement or even dealt with as a formal work. In view of the poor pertinence of propaganda of building an honest and clean government, the current implementation of a clean and honest culture mainly focuses on the top-down centralized learning of party and government organs and pays attention to the propaganda of leading cadres who ignore the nature of work and the work environment In the face of the temptation of corruption more "second hand", "third hand" leadership propaganda. In view of the single mode of construction of a clean and honest administration and the culture of incorruptible government, most of them are carried out in a solemn and sole form, lack of lively and vivid educational materials and loved forms of education, and make use of the rapid development of big data technology for the characteristics of different audiences. Carrier culture of clean government has a narrow channel and ineffectiveness.

3) Lack of evidence theory and insufficient prevention of corruption crime evidence

The theory of ametrism is a theory in Western criminology. The core argument is that under the premise of setting society's recognition of success as a similar standard, people are different in their ability to achieve this goal of success because of their class and status When people in a certain class and position can not achieve the socially recognized success goal by lawful means, they will have tension and may reach the point of crime through anger, defeat, greed and other emotions The goal is the emergence of an anomie status, which is the state of social esteem and social recognition of the means in the individual can not be met, the resulting disjointed state. In the crime of corruption, because officials are exposed to multiple temptations in their environment, both the economic status and the life style may destroy their firm willpower, shake their three concepts, and the anomie mentioned in the anomie theory appear to further evolve into achieve the goal of corruption crimes. Typical examples, such as former deputy secretary of Nanjing Municipal Party Committee and mayor Ji Jianye in his bribery case after the "repentance book" wrote: "With the promotion of office, power changes, status, improve their own party spirit, no realm of life Be synchronized to improve, on the contrary selfish thoughts in the soul of the expansion and expansion, envy the businessman's gold life [18].

In fact that the crime of anomie has the feature of "white collar crime" in corruption crime, the evidence of corruption crime is more difficult and harder to combat than the general crime, which is mainly due to the special covert evidence of criminal subject identity and the difficulty of retaining Subjects special difficulties in obtaining evidence, the special nature of the criminal investigation susceptible to interference, the crime of special evidence is limited. Crime body identity is particularly hidden and strong evidence is difficult to retain that criminal suspects are mostly corrupt criminal high-ranking state public officials, such people have rich social experience or close contact with the judiciary, familiar with the crime of corruption itself, the corresponding Legal provisions and investigation and handling procedures, so in the course of their crimes will use professional knowledge and social status to hide and destroy the evidence involved, making the prevention and control of corruption crime evidence collection more difficult. The special forensic difficulties of criminal objects are aimed at corruption corruption and the ownership of public property that infringes on the official duties of officials in state organs. There is no direct and specific victims, which makes the statement of the victims as the important evidence in traditional crimes absent. In addition, at the time of crime, only the actors and the bribery were present, making it difficult to obtain such evidence as witness testimony. The nature of the crime Special investigation susceptible to interference is due to the crime of corruption is usually not one or two people suspected of crime, is likely to involve the corruption behind the group has not been found, so corruption crimes are being investigated corrupt groups or stakeholders Trying to hinder the handling of the case through the hands of the right from time to time, leading to the evidence collected by the parties refused to plead guilty, string supply for the phenomenon. The special case of evidence of crime, fixed evidence and other restrictions, is aimed at most corrupt officials, many of these corruption offenses related to foreign deposits, assets and other evidence must be involved through judicial assistance or international conventions exist channels, there are long cases, The countries involved do not cooperate with the situation from time to time, making corrupt crime evidence, fixed evidence subject to multiple restrictions.

\section{B. The actual situation of prevention and control of corruption in China from the perspective of big data}

\section{1) The use of big data in detecting corruption crimes}

The introduction of big data into the field of corruption prevention and control, the use of big data technology found that corruption is the key to science and technology can act on judicial practice, good transformation and application will effectively avoid corrupt criminal interest groups asylum corruption crime led you to report Problems in channels and channels of corruption crimes, and clearing the way for the complete crackdown on corruption crimes have made remarkable achievements in anti-corruption progress since the 18th CPC Congress, especially after the 6th Plenary Session of the 18th CPC Central Committee, and will also greatly reduce manpower costs and save the judiciary Resources. After the 18th National Congress of the Communist Party of China, the crime rate in China has been rising steadily. According to statistics, in 2015, the overall characteristics of China's crime are "the number of criminal cases of property crimes has risen markedly and the number of criminal cases of fraud has varied."[19]According to the statistics of criminal cases filed by public security organs nationwide, "in 2015, there were a total of 6.22 million criminal cases of" robbery and cheating ", accounting for $84 \%$ of all criminal cases."[20]In 2016, one of the main features of crimes in our country as a whole remains as follows: "Frequently encroached upon property crimes are regional, occupational, and often falsified. Personal information leakage induces multiple types of precision-typed scams. Theft, fraud, robbery and robbery serious crime hair, high incidence, seriously affecting the sense of security and social harmony and stability. "[21] Can be seen in recent years, the types of recurrent and high incidence of crime in our 
country more concentrated, accounting for the vast majority of the total number of criminal cases. We usually deal with recurrent and multiple crimes in two ways: one is to crack down on "special operations" and the other is to follow the trends and laws of crimes committed in a certain area on the basis of the data reported by the Daily Police Intelligence Carry out a phased analysis and conclusion, and then conduct a comprehensive remediation of the criminal problems in the area. In recent years, a third approach has emerged that uses big data to prevent crime. "Huairou District of Beijing successfully predicted a theft case by using big data, cloud computing and scientific analysis models."[22]Shanghai public security organs use big data actual combat application platform to strengthen the comprehensive information judgment and investigation methods and enhance the initiative and precision strike capability. "Destroyed 589 evil gangs, arrested 2442 criminal suspects, cracked 598 criminal cases, an increase of $36 \%, 33.3 \%$ and $40.4 \%$ over the same period of last year."[23] In May 2016, based on the big data, Guangdong Provincial Public Security Department organized the province to launch a week-long "Hurricane 7" campaign to fight a series of criminal cases of "stealing and robbery". "346 suspects were captured within 7 days, 26 criminal gangs were destroyed and 26 series of" robbery and robbery "crime cases were uncovered, ranging from 456 cases.[24] The former two methods mainly tended to passive response afterwards, not to mention prevention and control in advance, nor long-term response mechanism. Some of the frequent crimes showed the phenomenon of "endless wildfire and spring breeze blowing again." Although the third big data measure has also achieved certain achievements, judging from the statistics of criminal cases filed by the public security organs nationwide in 2015, the effectiveness of the big data crime prevention and control technology at this stage is not obvious. The above data are still limited to ordinary cases. However, specific to corruption crimes, the accurate data can not be found for the relevant data, and accurate conclusions can not be drawn yet. However, it can be predicted that China may have achieved certain results in the prevention and control of corruption crimes. With the rise of big data technologies such as cloud computing, artificial intelligence and Internet + , the following functions can be highlighted in the discovery of corruption offenses using big data: 1. Prosecution agencies directly receive reporting information through the big data early warning platform and find corruption for the first time Crime; 2. The procuratorial agencies use the big data early warning function to filter out big data and information and avoid human control to ensure that all people are equal before the law; 3 . With the aid of big data communication, the reporter is kept confidential and the reporting cost is reduced.

\section{2) Big data in the fight against corruption crime application}

Statistics show that in 2017 the discipline inspection conducted by the discipline inspection and supervision organs in China in the first three quarters showed that there were 383,000 petitions filed by the discipline inspection and supervision authorities nationwide and 338,000 were punished in the first three quarters of 2017. Among them, cadres at and above the provincial level 56 people, bureau-level cadres more than 2,300 people. According to the circular, from January to September 2017, the discipline inspection and supervision authorities across the country accepted a total of 2,025,000 petitions and letters and handled 83,300 clues and handled 183,000 interviews and filed 383,000 petitions and 338,000 disciplinary sanctions (including party discipline Dispose of 283,000 people). There are 56 cadres at provincial and ministerial level and above, 2,300 cadres at bureau level, 14,000 cadres at the county level, 51,000 cadres at the county level, 63,000 general cadres, and 208,000 other personnel in rural areas and enterprises. From January to September 2017, the national discipline inspection and supervision authority handled 814,000 person-times using the "four forms" of supervision and discipline. Among them, the first form criticized education and received 473,000 interviews, accounting for $58.2 \%$ of the total number of people handled by the "four forms"; the second form disciplined, organizational adjustment 261,000, accounting for $32.1 \%$; the third Severe disciplinary disciplines, important positions adjusted 4.5 million, accounting for $5.5 \%$; the fourth serious violation of discipline suspected of filing 34,000 cases, accounting for $4.2 \%$ [25]. After the 19th NPC, many officials such as Lu Wei, Liu Qiang and Zhang Yang plunged into the horse, demonstrating that they will not relax their stamina after a thorough and solemn rule on the party. Nearly 20 middle management cadres such as Sun Zhengcai, Wang Sanyun and Xiang Junbo have been censored by the Central Commission for Discipline Inspection since 2017, of which 18 cadres at the provincial and ministerial level and above have been placed on file for examination. The 19th CPC Central Commission for Discipline Inspection also disclosed that the focus of punishment in the future is that since the 18th CPC National Congress did not converge and hold hands, the clues of the problems have been concentrated, the masses have been strongly reflected, leading cadres who are now in important positions and may even need to be promoted Leading cadres. Shows that our determination to fight corruption crimes is very firm, but the fight against corruption is not the fundamental crime prevention and control of corruption cases is the key. In the face of the problems such as the special concealment of the identity of the criminal subject brought by corrupt crime and the difficulty of retaining it, the special evidence collection of the criminal object, the special investigation of the nature of the crime being susceptible to interference and the limited special evidence collection of criminal cases, And departments have taken full advantage of the "mass", "diversity" and "high value and low density" features of big data technology to translate the clues obtained into fixed evidence to prevent corruption crimes. Can be seen in recent years, China's use of big data technology to prevent corruption crime landmark. 


\section{3) The application of big data in preventing corruption} crime

The theory of differential interaction holds that the effectiveness of building an honest and clean culture in the prevention of corruption crimes has a direct impact on the false identification of corruption crimes in the subconscious and further affects the effective prevention and control of corruption crimes. Relying on big data can effectively solve the problem of lack of awareness in the building of an honest and clean culture, lack of pertinence in propaganda of building an honest and clean culture, and lack of diversity in building an honest and clean culture. First of all, the importance of building a clean and honest culture is not enough because of the different emphasis attached by the leaders in the process of dissemination of information from below, and the diminishing of the effectiveness of information transfer, which directly causes the most primitive integrity The release of cultural information can avoid the different levels of leadership caused by layers of conduction and the diminishing of the effectiveness of information transmission. For example, at present, all Commission for Discipline Inspection have set up their own official Weibo, which can release the "Independent Commentary" and "Integrity Quotations" in the first place according to their priorities in the region; secondly, the solution to the problem of lack of pertinence in publicizing the culture of clean government can not Instead, it divided the focus of propaganda of building an honest and clean government at the official level. Instead, it made reference to the big data and summarized the areas prone to crime and multiple crimes of corruption in the past. They spread the propaganda of building an honest and clean government toward these areas, guided the prevention of corruption crimes with big data information In the end, the solution to the problem of lack of diversity in the building of a clean and honest culture should first of all abandon the concept of "solemnism" and combine the seriousness of the construction of an honest and clean government with the construction of a clean and honest culture in the workplace. To effectively carry out the construction of an honest and clean administration, we need to understand the current social hot spots with big data, and broaden the channels for building an honest and clean culture in various forms, such as micro-movies, comic books, hot comments and interactive topics, of different ages to ensure effective prevention of corruption crimes.

\section{THE BIG DATA ON THE EXISTING CORRUPTION PREVENTION AND CONTROL SYSTEM CHALLENGES}

Under the era of big data, the prevention and control of corruption crimes are faced with the opportunity of technological development. At the same time, the disadvantages of existing prevention and control systems include the lack of supporting information on corruption prevention and control, the single prevention and control of corruption crimes, the prevention of lag and lack of pertinence, and other issues have become increasingly prominent.

\section{A. Lack of information on corruption prevention and control aids}

A significant feature of big data is the realization of the search for information from people to find information from people, information to find information changes. This case handling corruption cases from man to case, from the case to the people, from the case to investigate the mode of reconciliation. That is, as long as the related information can be extracted and drawn, the specific information required can be estimated from the mass data.[26]The current corruption prevention and control did not catch the wings of big data technology. As far as prevention of corruption crime is concerned, the main source of information for prevention is the relevant information obtained by the criminal investigation department in the case handling department. In recent years, with the transformation from "investigation center" to "trial center" and the continuous promotion of "science and technology picking up", the technical means of investigating corruption crimes has been improved. However, the application of information technology, especially big data technology, insufficient. Compared with the increasingly concealed and increasingly high-intelligence corruption crime, the existing prevention and control of corruption crimes have not enough information on the deep-seated correlation hidden behind the Internet and new technologies, and are under-utilized and depleted. Due to limited information transmission by procuratorial agencies and the lack of a dedicated data mining and analysis team, big data helps to prevent and control corruption crimes at an initial stage, but the prospects are promising.

\section{B. Single prevention and control of corruption crime}

Thomas Friedman, winner of the Nobel Prize in economics, pointed out that in the process of globalization and informatization, with the progress of science and technology and the integration of social agreements (such as mobile phones, the Internet and open source programs), "the world is being wiped level". This article argues that in the field of big data, this "flat" is mainly reflected in the non-specific individuals using the Internet and other technologies to obtain information may become a reality. Through mobile phones, social networks, mobile payments and other means, each person is both the data maker, but also the owner of the data, and data is information. People leave traces of data at the same time, but also touch other people's data traces, which may include corruption prevention and control of crime. In reality, the prevention and control of corrupt data seem to be entirely a matter of specialized agencies. Prevention is borne by the department of crime prevention of post of procuratorial organs. Investigation and handling is the duty of anti-corruption and anti-dictatorial departments. In this "world is flat" society, in addition to reporting clues, there is no room for people's participation in the prevention and control of corruption crimes. This is not consistent with the general principle of prevention and control, prevention, combination of specializations and groups, relying on the masses in public order prevention and control and public participation is an important part of anticorruption. With the departure of the masses, the prevention and control of corruption crimes will be greatly reduced. "The police are only part of criminal justice, the criminal justice 
system is only part of the government and the government is part of society, and only effective mobilization of society and public participation can effectively control crime."

\section{Prevention of being lagging and not targeted}

Prediction is at the core of big data, and it applies mathematical algorithms to massive data to predict the likelihood of something happening. As a result of massive data support, combined with mathematical statistics principle, the forecast result is accurate to incredible. Typical examples: In 2014, Microsoft's big data team accurately predicted the World Cup, Wal-Mart's data analysis shows that the combination of beer and urine will greatly enhance the sales of two products, the current corruption prevention and control work has serious lag characteristics, "follow-up, give top priority" is its accuracy description. This is a typical "remedial measure" prevention work is actually based on the crime cases have also occurred as material, to do anatomical sparrow-style research and put forward prevention and control measures, and rarely pay attention to the prevention and control of the object before the incident content, The relationship between property changes and job-related crimes. Prevention and control of corruption crime is seriously lacking in the application of big data speculation techniques and it is difficult to formulate a specific prevention and control countermeasure.

\section{Breeding black exist}

Technology allows the world data, data records the world, which produced big data. Technology such as mobile phone, Internet, social networking, APP has become an indispensable part of people's lives, and the use of these technologies will produce a large amount of data traces and be saved. Through the data mining analysis, you can restore a person's behavior, to some extent, all human behavior can be traced back through the data, restore. Due to the low use of information technology, the current prevention and control of corruption crimes are extremely difficult to find and detect corrupt and intelligent criminal activities with high intelligence and strong concealment, breed the crime black numbers and make the potential corrupt criminals hold the chance. And then to defy the law is not conducive to the prevention and control of corruption crimes. "We want to control a crime, as long as the penalties to be deprived of more than criminals get through crime." The key to deterrence is that all crimes can be investigated and punished according to law, because rational criminals are afraid Harsh sentences that dare take the risk of committing a crime because they consider themselves vulnerable to legal loopholes that can not be captured. Determining penalties is more important in controlling and reducing crime than in criminal sanctions. "[27] We must seize the goal and task of resolutely curbing the momentum of the spread of corruption, consolidate the overwhelming achievements of anti-corruption, reduce the stock of corruption and focus on curbing increases. The relationship between the stock and the increment, the stock can not be reduced, the increment is difficult to contain, the increment can not be contained, the stock is difficult to digest.

\section{E. Prevention and control measures need to be optimized}

The value of big data does not lie in the machine that analyzes the data, but in the data itself and how we use the data Once the statistics and the current large-scale data fusion, will subvert a lot of our original thinking, found interesting rules. Such as through the model design, combined with a person shopping, browsing the web, activity trails, medical treatment, catering and other data can be drawn out the characteristics of the person's data to find their hobbies, physical condition and other personalized information to draw more than I understand myself Data conclusion, which is the "data decision-driven" principle that various commercial fields are applying at present. At present, the prevention and control of corruption crimes are mainly through conventional air defense strategies such as analyzing cases, warning cases that have been decided upon, and serving sentences of criminals. On the one hand, they lack the pertinence and are difficult to find the traits of prevention and control before crimes occur. On the other hand, this kind of prevention and control mainly urges the target to "not dare to rot" through the warnings and policy education in the cases that have been decided, and "do not want to rot ", and it is difficult to objectively form a" non-rotten "environmental mechanism. Corruption crime prevention and control system is not adapted to irreversible big data flow.

\section{THE ERA OF BIG DATA CORRUPTION PREVENTION AND CONTROL SYSTEM TO ACHIEVE THE PATH}

The torrent of big data is irreversible. His mode of thinking, which profoundly affects people's production, life style and cognitive world, brings opportunities for technological development in the prevention and control of corruption crimes. This paper argues that the prevention and control of corruption crimes in the age of big data the system can start with the following dimensions:

\section{A. Open up new ideas, train team of experts}

Idea-guided behavior, behavior decisions result. 1. Form big data thinking. Big data is not a simple analysis and processing. The value of big data industry often depends on three aspects: thinking, technology and data. Thinking is the key to determining the application of big data. Big data thinking requires us to start from the needs of our own work, acutely discover new ways of data application, learn from multidimensional perspectives, tap the potential value of data in specific industries, and enhance the ability to analyze and judge related information. Under the era of big data, only by setting big data thinking can we truly tap the value behind it. Due to the application of new technologies, corruption prevention and control targets inevitably leave traces of data and are not controlled by the parties. The effective use of the data behind these data to formulate personalized prevention and control measures and implement accurate corruption offenses is of paramount importance effect. The main body of prevention and control of corruption crime must establish a data-driven prevention and control concept. Subjectively, we must recognize the advantages and irreversibility of big data so that we can actively use big data in our work and abandon "one pen, one mouth and two legs" Prevention and control mode. Objectively, we should realize the professionalism of big data 
technology itself, create various conditions for prevention and control subjects to learn and use big data, and cultivate comprehensive corruption prevention and control personnel for prevention and control, investigation and data utilization. 2. Training team of experts. It is imperative to set up a group of experts in corruption prevention and control. In the course of training, we should insist on "going out", go to the more mature countries and regions to conduct research on crime prevention and control of big data corruption, and learn from the results and exposures reflected in its practical application, in light of local conditions in our country, In line with their own theory on this. By excavating and collecting the data and information stored in various industries and analyzing the value behind the excavation, we apply it to the prevention and control of corruption crimes such as the formulation of prevention and control measures, the discovery of criminal clues, the breakthrough of criminal confessions and the acquisition of criminal evidence In all aspects, to achieve the best prevention and control.

\section{B. To build a large database of corruption prevention and control}

The accumulation of data is a process of quantitative change to qualitative change. When the data is not enough, he may be inaccessible fragments. However, with the accumulation of data beyond a certain threshold after the debris presented by the overall law will be to some extent be revealed. The key to big data is the data itself and the use of data. The premise of constructing the prevention and control system of corruption crimes under the era of big data is to collect and integrate massive data and information and form a special analysis and judgment team. 1. Construction of a large database of corruption prevention and control, follow the "side mining, construction, use, adjustment of the edge" approach, will be close to the actual, effective use of data into large databases. Mainly include the following information: (1) The object of prevention and control of corruption crimes Passively documented social information, including flight trains, mobile payments, bank cards, online shopping and other information, make full use of the mainstream network platforms such as Baidu, Tencent, Taobao, Jingdong, and so on, using unstructured information in different categories and different fields by means of paid purchase, voluntary offer, cooperation and sharing, etc. (2) Integrating and sharing government official management information including post responsibilities, appointment and dismissal documents, individual performance of duties, Public resource transaction management, etc. For the public security and other classified information, special information such as public access and green channel can be used for transmission. (3) Corruption criminal data information, including criminal clues over the years, investigation and handling of cases, personnel involved and handling of the results, The main behavior and so on. This database must meet the conditions of large quantity, comprehensive coverage and unstructured structure, in fact, it is also different from the traditional database. Only when the body mass is large enough, the field involved is wide enough and the unstructured features are obvious enough to dig out the value behind the data, we can predict the crime trend based on the data so as to provide targeted and individualized prevention and control measures for crime prevention and control. 2. Set up big data R \& D team. In the hardware facilities are protected at the same time, but also need to screen data analysis capabilities, the relevance of information to determine the relevance of professional and technical work to be strengthened. Microsoft is a big data research center made an accurate prediction of the 2014 World Cup matches; Wal-Mart through its data processing center came to beer and urine will put together to increase sales conclusion; Alibaba's data center based on the user's Web browsing, shopping experience to accurately push the user "guess you like" content. If the big database is the premise of decision-making, then the analysis of large databases to judge the team is the key decision-making. The core of corruption prevention and control using big data lies in the effective prevention of corruption crimes that have not occurred and the exact blow to the corruption crimes that have occurred. In the meantime, we can give a clear signal to potential corrupt elements: Hand stretched, lucky or not. The way to realize this goal is to excavate and analyze the massive information, through the means of mathematical model, statistical probability and other means, to make effective prediction of the corrupt criminal correlation data and accurately recover the trace of the data left by the criminal act. The direct conclusion is that prevention and control departments should set up a special R \& D team to enhance their ability to analyze and judge relevant information, expand their thinking on preventing and controlling corruption crimes, and in particular, to reverse a single cause and effect. Inductive thinking is data-related thinking. Department of different information isolated island data center found that eventually applied to all aspects of prevention and control of corruption crimes to achieve prevention and control to maximize effectiveness. At the same time, data security and personal privacy are essential. In the course of collecting and using data, we must establish a sound information security system, strengthen the management of data usage, fully test and record the usage, and block the suspicious operations in a timely manner through intelligent operations to achieve security Use data sequentially. 3. Erecting cloud platform, gathering massive data. At present, we can consider setting up corruption prevention and control of cloud computing center and increase business data collection point of view.

\section{Open the main body of prevention and control}

Public participation is an important part of anti-corruption. "Limited energy and infinite force of manpower" have become the consensus in the area of crime prevention and control. The prevention and control of corruption crimes need to adhere to the principle of "combination of experts and the masses." In the era of big data, each person creates data and is recorded by data. Individuals in different social sectors knowingly or unknowingly come into contact with various data. These include the data traces left by the object of corruption prevention and control and the data before crime can be used to prevent corruption crimes, the data left behind by the commission of crime can be used to combat crime. The problem is that these corruption prevention and control of corruption and its valuable data like scattered space scattered in the vast majority of big data, specialized corruption prevention and control agencies even if full desperation is difficult to 
obtain all the value data, the public on corruption prevention and control The potential role in the big data era more prominent. First of all, the law pop-up gas, publicity to the private sector. Through publicity on the streets, mobile phone pushing, community assistance and APP dissemination, the public is allowed to squeeze crowded space for corruption crimes so that the general public consciously fight corrupt practices and mainly participate in various activities of the state toward zero tolerance of corruption crimes. This article agrees with the "Preventive Postal Road" that is being carried out across the country activity [28].We can learn from this form to carry out prevention and control of corruption crimes in virtual space. Second, smooth the channels for public participation in corruption prevention and control and reduce public participation in corruption prevention and control costs. In particular, with the help of new Internet technologies, ordinary people should be involved in the prevention and control of corruption crimes, that is, they should be efficient and safe. However, they should establish effective cooperation mechanisms for prevention and control of corruption crimes with the mainstream internet platforms and ensure that related data concerning the prevention and control of corruption crimes Timely feedback prevention and control departments. Once again, strengthen the masses foundation. Adhering to the "security foundation in the people, the source of strength in the people", take a scientific approach to consolidate the foundation for universal security. At any place, the masses are made aware of their important role in safeguarding the overall interests of the public security in their own interests. Everyone is responsible and everyone contributes to it. Efforts should be made to cultivate the concept of "one glory and one prosperity" and "one loss and all loss" for the industries, units and areas under its jurisdiction. Finally, disseminating corruption warning cases with a high-quality media platform has made every possible perpetrator of corruption a clear idea of the consequences of implementing corruption offenses.

\section{To develop accurate prevention and control measures of corruption crimes}

Precautionary measures to prevent and control corruption are the preconditions to realize the prevention and control of corruption crime. The features of large-quantity forecasting of big data provide the technical possibility for this. 1. To build "not rot" big data prevention and control pattern. The production and collection of big data in fact formed a data map of behavior-centered people, which could infer the social relations of the perpetrator's hobby, the circle of friends, the relationship network and even the hidden lover. These data objectively exist in the third party, the parties are hard to destroy. Corruption crime prevention and control departments should focus on the prevention and control of the object, delineate the "data person" of each object, and adjust the contents of the "data person" to make it objectively afraid to commit crimes according to changes in information generation. 2. Develop personalized prevention and control measures. The use of big data to launch personalized services has become common practice in the commercial area, the crime prevention and control departments of corruption can be based on the control of data objects over time, based on their industry sectors, the situation of job-related crimes in the region, with big data platform Analysis of conclusions, put forward personal control measures. 3. Proactive prevention of corruption crimes. At the core of big data is "catching the present" and "predicting the future", which makes it possible for the prevention of corruption to follow up and change into antecedent prediction. According to the big data thinking mode and processing method, through the collection and analysis of big data, the factors associated with corruption crimes are identified, and as long as this factor appears, corruption crimes have occurred or are about to occur. Such as collecting and analyzing data of air-defense target bank deposits, securities funds, vehicle information and real estate information, etc., it is possible to judge in advance whether the property is abnormal or not; by analyzing a large amount of data such as accommodation records and aviation records of prevention and control targets, Object expenditure direction, and other records. Focus on significantly abnormal data and initiate precautionary measures if necessary [29].

\section{E. Enhance the driving force, research and development of intelligent tools to reduce or eliminate the crime black}

"Workers want good things, must first sharpen." Gathering massive data resources is the foundation of big data prevention and control system. On the basis of this, some functional tools are needed, and various algorithms are used for analysis and modeling to find out the inherent and necessary causal relations behind all kinds of data so as to truly construct the prevention and control system against corruption in big data. Instead of being sentenced to death, corrupt criminals fear the probability and risk of being caught after they commit the crime. Bellaria states in Crimes and Criminal Law that "the certainty of penalties is more important in controlling and reducing crime than in the severity of penalties." The existence of black corruption crimes is exactly the opposite of this argument. The existence of a large number of corruption crimes black number seriously impact on the prevention and control of corruption crimes, to some extent, encourage potential corrupt criminals to defy the law. It is necessary to firmly believe that the higher the means of crime, the more intelligent the more traces of data left behind and difficult to destroy. Corruption criminal investigation departments should store large amounts of data stored in incoherent media information to extract the corrupt criminal information to Objects for CITIC to reproduce its relationship circle, the living circle, the interests of the delivery circle, the trajectory of activity and other data, outline the data maps of air defense objects for the clues to find, gout to obtain evidence of fixed crime identified under the data support to reduce or eliminate corruption crime black Improve the effectiveness of prevention and control of corruption crimes from the perspective of combat. In view of this, we can enhance the driving force, develop tools for trajectory analysis and create a "fingertip" resource system, and even achieve the goal of reducing or even eliminating the crime blacks.

\section{CONCLUSION}

Humans have quietly entered the era of big data, the data itself does not add any value, its main performance is reflected in how to deal with, analyze and make use of these data. The use of big data to drive corruption crime governance decision- 
making for future corruption crime governance decisionmaking to achieve the scientific and technological possibilities, corruption crime prevention and control departments to comply with the development trend, seize the opportunities for development, the application of big data, relying on big data, data-driven decision- Let the data support anti-corruption, to achieve the best prevention and control of corruption crimes. Of course, while this technology brings about a great change of ideas, it also brings many problems such as privacy and infringement of personal information to the corruption crime governance itself. Therefore, it faces many disputes and questions. In any case, the original extensive prevention and control decision-making model of crime will inevitably shift towards a refined and scientific decision-making model of criminal governance. The data sampling and analysis techniques of small samples will inevitably be replaced by data mining and intelligence research of big data replace. In the process, the risk of technology itself will be gradually overcome by the development and evolution of technology itself. The focus of future research should be on how to expand the application of big data technology and gradually bring its value into full play in the field of broader crime control and crime prediction.

\section{ACKNOWLEDGMENTS}

Fund Project: In this paper, Yuehong Wu presided over the 2016 China Postdoctoral Science Foundation Program "Confession of Penalties and Penalties from the system of procedural control" (project number: 2016M602437),Guangdong Philosophy and Social Science Thirteen Five Year Plan 2017 disciplines co-construction project "big data era Under the Guangdong comprehensive governance according to law practice province "(project number: GD17XFX13) ,2018 Annual Guangzhou City's Philosophy and Social Science Development Youth Program for the Thirteenth Five-Year Plan" The Practice of a Comprehensive Legal Administration of Guangzhou in the Era of Big Data" (Project Number: 2018GZQN28) and the Year of the Thirteenth Five-Year Plan of the 2017 Guangzhou City Philosophy and Social Science Research Project (Project No. 2017GZWT23) "Physical and empirical studies on the anticorruption efforts in Guangzhou since the 18th National Congress" phase of the research results,.

Yuehong $\mathrm{Wu}$, Guangdong University of Technology Institute of politics and law teacher, postdoctoral researcher, research direction: litigation law, Hong Kong and Macao basic law, criminology.

Yaming Fang, Associate Professor, College of Political Science and Law, Guangdong University of Technology, Research Interests: Constitution and Administrative Law.

\section{REFERENCES}

[1] Xu Jihua, Feng Qina, Chen Zhenru: "Wisdom Government -big data era of governance," CITIC Publishing House 2014 edition.

[2] Ministry of Industry and Information: "China will build a national integrated big data center", set forth at
http://news.163.com/17/0517/19/CKLO3JBM00018AOQ.html, accessed on May 18, 2017.

[3] Zhang Yuhong: "taste big data", Peking University Press, 2016 edition

[4] Nicole Laskowski. The big data architecture dilemma for CIOs. TechTarget. http // searchcio.techtarget.com / feature / The-big-dataarchitecture-dilemma-for-CIOs.2014-08

[5] Chinese Court Data As of the end of 2012, the data comes from Chen Sheyun: "Study on the reform of the classification of court personnel management", Law Press, 2014 edition, p. 85

[6] Li Guojie, Cheng Xueqi: "Big Data Research: Major Strategic Areas for Science, Technology and Economic Development in the Future - Present Status and Scientific Considerations of Big Data", Proceedings of the CAS, 2012, No.6.

[7] Big Data, at https://baike.so.com/doc/5374131-5610149.html, November 4, 2013.

[8] Wang Fang: "Prevention and Control Countermeasures of Internet Financial Crimes in Big Data Era", in "Time Finance", No. 1, 2016.

[9] Duan $\mathrm{Zu}$, Tian Hong editor: "big data foundation and management", Tsinghua University Press, 2016 edition.

[10] Duan $\mathrm{Zu}$, Tian Hong editor: "big data foundation and management", Tsinghua University Press, 2016 edition

[11] See Zhigang Shan: "" on the promotion of big data development action outline "interpretation, URL: http://news.xinhuanet.com/info/201509/17/c_134632376.htm

[12] Wu Zongxian: "Western Criminology (Second Edition)", Law Press 1990Edition, p. 409.

[13] Joe Telford: "Report and Anti-Corruption", China Social Press, 2007, p. 1 .

[14] See http://www.gywb.cn/content/2014-12/18/content_2052834.htm, last accessed December 30, 2017

[15] Jin Gaofeng and Bai Penghui: Analysis of China's Criminal Situation in 2015 and Forecast for 2016, Journal of Chinese People's Public Security University (Social Science Edition), 2016, No.3, P. 27.

[16] The Ministry of Public Security of the People's Republic of China has deployed a special campaign to crack down on the crime of "stealing and robbing" .http //www.mps.gov.cn/n2253534/n2253535/n2253537/c5171575/content.ht $\mathrm{ml}$.

[17] Jin Gaofeng, Wang Yue, Li Yishang: Analysis of China's Criminal Situation in 2016 and Forecast for 2017, Journal of Chinese People's Public Security University (Social Science Edition), No. 2, 2017, p.6.

[18] Xinhua: Beijing police use big data to predict crime trends, http://news.xinhuanet.com/legal/2014-06 / 17 / c_1111188554.htm.

[19] Dongfang: Shanghai Public Security Big Data accurately crack down on crimes affecting the safety of citizens significantly decreased.

[20] NetEase Finance: Guangdong application of big data to crack down on robbery arrested 1043 suspects a week.

[21] Xinhua, the first three quarters of discipline inspection and supervision organs disciplinary 338,000 people including 56 provincial and ministerial level cadres http://news.sina.com.cn/o/2017-10-29/docifynffnz3440657.shtml,2017 October 29,

[22] Big data thinking of the ten core principles", http://www.sohu.com/a/122884667_470097, the last access date: December 30, 2017

[23] Ye Rui, Rao Jing: "Corruptive Punishment," "Severe Punishment" and "Laws and Regulations", "Journal of Southwest University for Nationalities (Humanities and Social Sciences)" 2016, No.12.

[24] On September 19, 2016, in order to strengthen the work cooperation between procuratorial organs and postal services at all levels and establish a service network of crime prevention volunteers covering urban and rural areas, the Supreme People's Procuratorate AntiCorruption Administration and China Post Group Corporation jointly issued the "Jointly Launched" Guiding Opinions on Preventing Postal Envoys from Post Crimes since September 19, 2016.

[25] Deng Shugang: "The use of big data technology to promote job-related crime prevention work," "People's Procurator" 2014 the sixth period. 